\section{Commentary on: Management of cleft lip and palate in Egypt - A national survey}

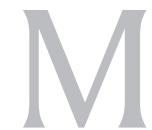

any countries have made an effort to study the trend, protocols and outcome of management of cleft lip and palate in their individual country. This study is on similar line to study the trend and protocols for the management of cleft lip and palate in Egypt. While I appreciate the author's efforts, there are, however, shortcomings of this study: (1) only plastic surgeons have participated rather than surgeons from all specialties who do cleft surgeries and (2) epidemiology details about cleft lip and palate prevalence and incidence in Egypt, and how many of them able to reach for the treatment is needed to put this article in proper context.

As per the outcome of this study, there are definitely certain areas, which demand appropriate attentions, change of protocol and addition of skills to the cleft team. The popularity of primary gingivoperiosteoplasty with primary cleft lip repair shows that nasoalveolar moulding (NAM)/infant orthopaedics is being widely popular and practiced. There are two issues here: one is NAM/infant orthopaedics is an additional labour incentive intervention which has not shown any long-term better outcome in nasolabial aesthetics or maxillary growth ${ }^{[1-3]}$ and any team using this cumbersome procedure needs to think about the long-term benefits and burden of care before implementing, especially with limited resource availability. ${ }^{[4]}$ A good surgeon with skilled hands can certainly avoid the need of NAM. Second, primary gingivoperiosteoplasty should not be done as it has proved to have disastrous effect on maxillary growth, and majority of centres across the world have stopped this procedure. ${ }^{[5]}$ The another glaring issue is two-flap push-back procedure is being still done by $56.3 \%$ surgeon, in spite of multiple studies showing very poor growth outcome following this technique.

The present study shows very general trend but helps to bring out some ground reality of high rate of fistula. In addition to this, a less number of patients receive alveolar bone grafting and velopharyngeal insufficiency correction. The National Cleft Association can take clue from these data to start discussing important issues to improve the outcome of cleft management and avoiding or reducing the unnecessary intervention like NAM which has more adverse effect and beneficial.

Similar studies are important, especially in countries with limited recourses to form guideline to provide the best outcome without increasing the burden of care keeping sensitivity to the local culture and aspiration. Such studies also provide the information regarding the probable problems faced by the professionals across the country or some specific part of the country.

Cleft lip and palate is one of the reconstructive surgeries that have achieved significant attentions not only from medical professionals but also from society as large due to it visibility, treatability and affecting children. Approximately $60 \%-70 \%$ of children are being treated either by government, insurances or non-government organisations (NGOs). ${ }^{[6]}$ When the management is supported by any of the organisations, it is obvious that scrutiny of the outcome of management is expected sooner than later.

In India, over the time the cleft management is concentrated in cleft centre which has morphed/forced to be due to the support of NGOs creating centres with large number of cleft surgeries. Many NGOs are also supporting additional services such as speech and dental in addition to surgical care. It will be very informative to bring out detailed study regarding the protocol and outcome of the management of cleft lip and palate from various centres in India.

\section{Jyotsna Murthy}

Department of Plastic Surgery, Sri Ramachandra Institute of Higher Education and Research, Chennai, Tamil Nadu, India

Address for correspondence: Prof. Jyotsna Murthy, Sri Ramachandra Institute of Higher Education and Research, Chennai, Tamil Nadu, India. E-mail: murthyjyotsna@gmail.com 


\section{REFERENCES}

1. Prahl C, Prahl-Andersen B, van 't Hof MA, Kuijpers-Jagtman AM. Infant orthopedics and facial appearance: A randomized clinical trial (Dutchcleft). Cleft Palate Craniofac J 2006;43:659-64.

2. Bongaarts CA, Prahl-Andersen B, Bronkhorst EM, Prahl C, Ongkosuwito EM, Borstlap WA, et al. Infant orthopedics and facial growth in complete unilateral cleft lip and palate until six years of age. (Dutchcleft) Cleft Palate Craniofac J 2009;46:654-66.

3. Liou EJ, Subramnium M, Chen PK. Progressive Changes of columella length and nasal growth after nasoalveolar molding in bilateral cleft patients: A 3-year follow-up study: Taiwan Plast Reconstr Surg 2007;119:642-8.

4. Pai BC, Ko EW, Huang CS, Liou EJ. Symmetry of the nose after presurgical nasoalveolar molding in infants with unilateral cleft lip and palate: A preliminary study. Cleft Palate Craniofac J 2005;42:658-63.

5. Hsieh $\mathrm{CH}$, Ko EW, Chen PK, Huang CS. The effect of gingivoperiosteoplasty on facial growth in patients with complete unilateral cleft lip and palate. Cleft Palate Craniofac J 2010;47:439-46.
6. Gopalakrishna A, Agrawal K. A status report on management of cleft lip and palate in India. Indian J Plast Surg 2010;43:66-75.

This is an open access journal, and articles are distributed under the terms of the Creative Commons Attribution-NonCommercial-ShareAlike 4.0 License, which allows others to remix, tweak, and build upon the work non-commercially, as long as appropriate credit is given and the new creations are licensed under the identical terms.

\begin{tabular}{|l|l|}
\hline \multicolumn{2}{|c|}{ Access this article online } \\
\hline Quick Response Code: & Website: \\
\hline
\end{tabular}

How to cite this article: Murthy J. Commentary on: Management of cleft lip and palate in Egypt - A national survey. Indian J Plast Surg 2018;51:296-7. 